POLLACK PERIODICA

An International Journal for Engineering and Information Sciences

DOI: $10.1556 / 606.2020 .15 .1 .22$

Vol. 15, No. 1, pp. 233-240 (2020)

www.akademiai.com

\title{
NEW STRUCTURE IN THE HISTORICAL CONTEXT CASE STUDY: CONTEMPORARY SHOPPING MALL IN THE HISTORIC CENTER OF PRIZREN
}

\author{
Besa JAGXHIU \\ Faculty of Construction Engineering and Infrastructure, University for Business and \\ Technology, Kalabria nn, 10000 Prishtina, Kosovo, e-mail: besa.jagxhiu@ubt-uni.net
}

Received 2 January 2019; accepted 20 June 2019

\begin{abstract}
The historic centers to retain their liveliness and vibrancy should be able to grow and change. It is a big challenge for the contemporary architecture to balance the socio-economic needs of the city and its community in one hand, and protection of the cultural heritage on the other. The aim of this study is to analyze the incorporation of the new structures in the historical context. How can the new structures harmoniously be incorporated in the historic centers without endangering their cultural heritage values? The paper discusses how to design a new contemporary shopping mall in the Historic Center of Prizren in order to create an attractive area and at the same time avoiding deterioration of the historical place.
\end{abstract}

Keywords: New structure, Historical context, Cultural heritage values, Contemporary shopping mall, Historic Center of Prizren

\section{Introduction}

The historic centers to retain their liveliness and vibrancy must be able to grow and change. It is a big challenge for the contemporary architecture to balance the socioeconomic needs of the city and its community in one hand, and protection of cultural heritage on the other. It is important to create high-quality designs for historic centers in order to create a unique sense of place and attractive areas for residents, business owners, and visitors.

All measures taken in the historical areas are aimed at providing a balance between the interests of preservation and those of use. While the protection of the valuable cultural heritage is given priority, the integration of the historic buildings into a vibrant 
urban organism is regarded as equally essential [1]. The relationship between new architecture with its historical context is determined from the values assigned to the meaning of its heritage architecture and consequently its modern interpretation. The issue of the interrelation between the new and old architecture in the urban fabric are crucial in all cities, which represent physically the combination of the historical part of corridor streets, grid organization of the roads, squares, green public spaces, freestanding public buildings and buildings articulated in a line with a main façade [2]. The problematic of designing a building among a group of historical buildings is a complex architectural design process [3].

Cities are in a continuous process of change and readjustment of their different parts, which are spontaneously developed or deliberately planned under different socioeconomic, environmental and political conditions in different historical periods [4]. Historic cities are host to exciting historical sites, outstanding heritage buildings, and unique local cultures: these represent a country and can be a source of pride [5]. Therefore any new design and intervention in these historical places should be done without endangering their cultural heritage values.

The issue of urban development of the historic centers requires strategic thinking. It includes self-sustainable mechanisms, strengthening self-organization and financing of the cities, collectively. Nowadays cities face challenges in all three domains that necessitate strategic thinking on the local, national and EU levels alike [6].

\section{Background}

The city of Prizren is one of the oldest settlements in Kosovo and in Eastern Europe, located in the middle of the ancient Venice-Istanbul trading route, which has always been a crossroad of trade and culture for the whole region [7]. The Historic Center of Prizren is the most outstanding zone of urban heritage in Kosovo, with valuable traces of diverse historical and cultural heritage. The cultural heritage of Prizren reflects the wonderful history of a city with a culture that stretches throughout the centuries up to the present day [8]. In figure 1 is presented a view towards the Stone Bridge and river Bistrica, Sinan Pasha Mosque and in the background the castle of the city (Fig. 1).

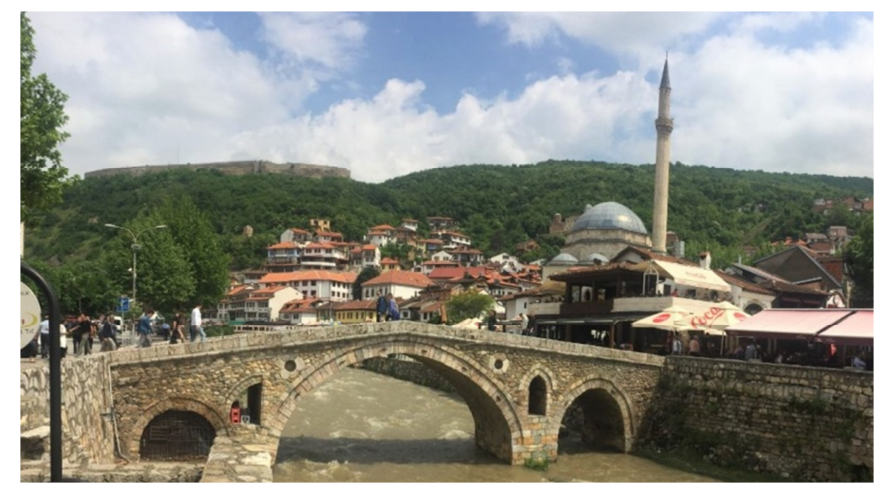

Fig. 1. Overall view of the Historic Center of Prizren (Photo: Besa Jagxhiu) 
Based on Conservation and Development Plan for the Historic Zone of Prizren, 2008, [9] the historic center is divided into eight sub-zones: 1. Traditional Market Zone; 2. High Building Blocks Zone; 3. River Bank Zone; 4. Nënkalaja (Under Castle) Zone; 5. Commercial Axe Zone; 6. Mixed Use and Housing; 7. Housing (Organic) Zone; 8. Housing (Construction) Zone (Fig. 2). The Historic Center of Prizren includes about $30 \%$ of the city, with 1377 cadastral areas in the center of city and 141 around the Fortress. It is very rich in monumental buildings, from which, 12 Mosques, 3 Tekkes, 2 Türbe, 3 Buildings of Serbs Orthodox Church, 8 Buildings of Complex of Episcope Residence, 13 Mills and Sources, 5 Nishan, 10 Public Buildings, 1 Sacral Catholic Building, 55 Housing Buildings, 4 Educational Institutions, 1 Natural Rarities, and 4 Architectural Complexes.

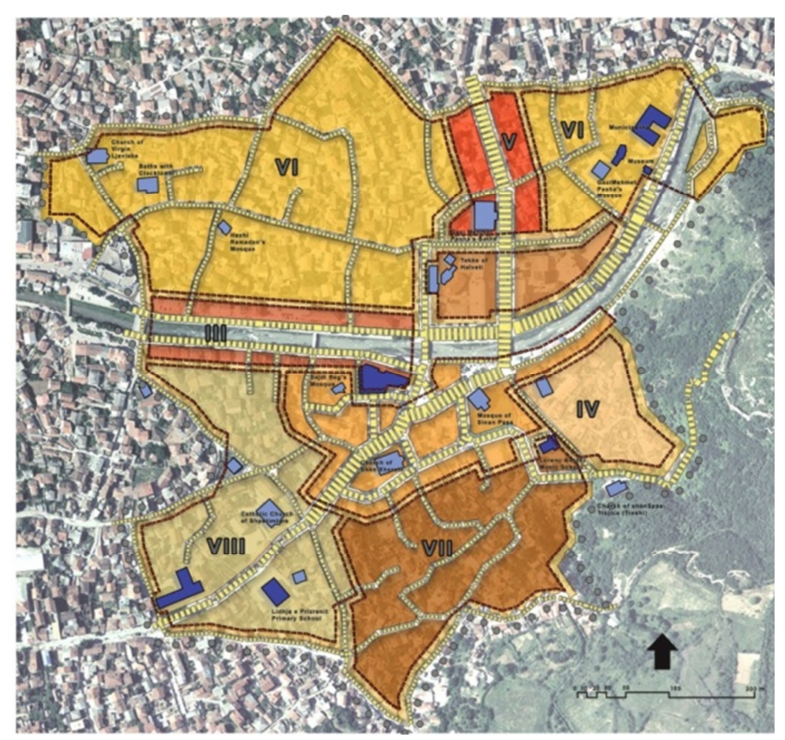

Fig. 2. Subzones of the Historic Center of Prizren [9],

I. Traditional Market Zone; II. High Building Blocks Zone; III. River Bank Zone; IV. Nënkalaja (Under Castle) Zone; V. Commercial Axe Zone; VI. Mixed Use and Housing; VII. Housing (Organic) Zone; VIII. Housing (Construction) Zone

The aim of this study is to analyze the incorporation of the new structures in the historical context. How can the new structures harmoniously be incorporated in the historic centers without endangering their cultural heritage values? How to design a new contemporary building in order to create an attractive area and at the same time avoiding deterioration of the historical place? The case study is the design of a new contemporary shopping mall in the Historic Center of Prizren.

\subsection{Case study: shopping mall in the Historic Center of Prizren}

The shopping mall is located in the heart of the historic center of Prizren, in the traditional market zone, in Shadervan Square. On the northeastern side it is oriented 
towards Stone Bridge and river Bistrica, on the southeast side overlooking the St. George Church, while on the front is overlooking the Sinan Pasha Mosque and the castle of the city, (Fig. 3).

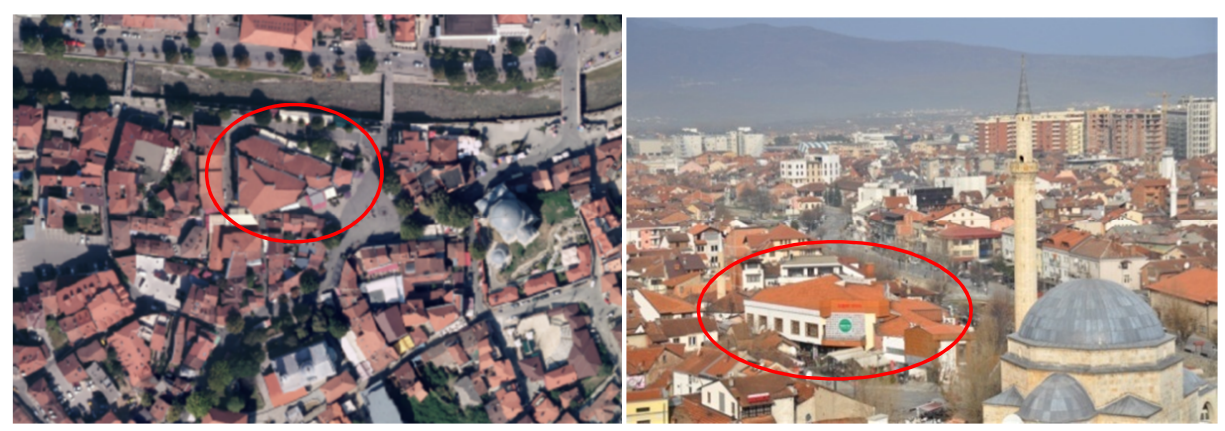

Fig. 3. Location of the shopping mall in the Historic Center of Prizren left [10], right (Photo: Besa Jagxhiu)

The urban fabric of the area in which the building is located is characterized by small traditional craft trade, commercial type buildings, located in sequence and attached to each other, with one or two stories. The structure of these buildings is mainly of massive wall structure or concrete, in harmony with the authentic urban architectural features of the city. The front facade of the premises is with wooden shop windows and entrances, while the sloping wooden roofs, with two or four pitches, are covered with traditional red clay tiles. The traditional market zone is a pedestrian zone, with local stone pavement streets, Fig. 4.

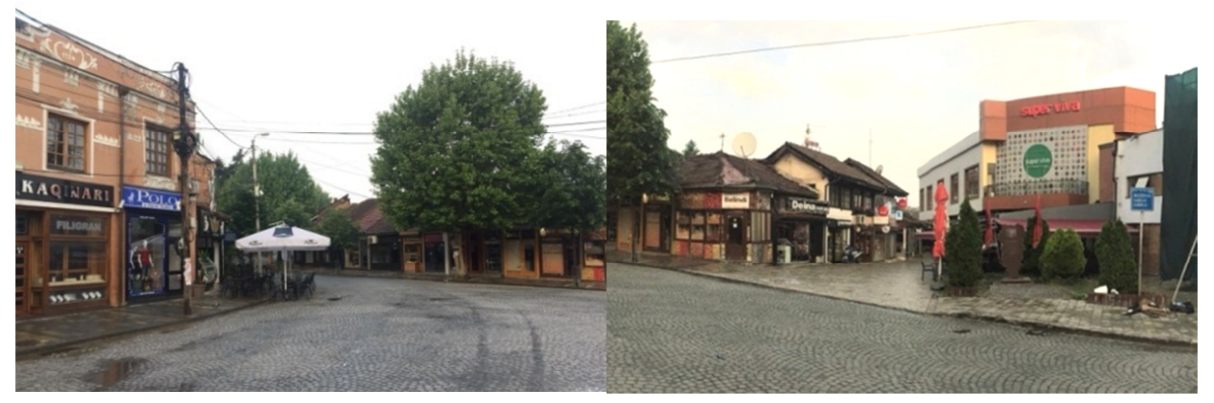

Fig. 4. The urban fabric of the traditional market zone; overall view (left), comparison with the shopping mall (right), (Photo: Besa Jagxhiu)

Unlike these characteristic features of the area, the shopping mall facility has a much larger volume compared to other surrounding buildings; the area has about $3200 \mathrm{~m}^{2}$, Fig. 3, lying on two floors. The architectural structure of the building, facade, and construction materials are not in harmony with the architectural and urban features of the area, Fig. 4, on the right. Despite the amazing surroundings, the building itself does not have good views of the river Bistrica, St. George Church and other monuments of 
the historic center. Also based on the conservation and development plan for the historic zone of Prizren, is considered in disharmony with the architectural character of the area.

Looking back at the history in the same place, it used to be the old traditional handicraft center, one of the best know centers in the region. In addition to its primary function for the economic development of the city, it has also played a very important role in the social life of the city as a place for meetings and holding various social activities. Unfortunately after World War II, from the reign of settlers, who never understood the values of the cultural heritage of the city, with the urban plans, which had the purpose of developing a so-called 'new urban structure' over inherited traditional values, resulted in the destruction of the city's historic nucleus. With the motto destroy the old and build a new, also this old center has been completely destroyed in order to construct the new shopping mall, thus losing the most authentic parts of the Prizren's cultural heritage. In Fig. 5 on the left is presented the old traditional handicraft center, which was destroyed in years 1967 in order to build the new shopping mall, on right, in disharmony with the urban character of an area.

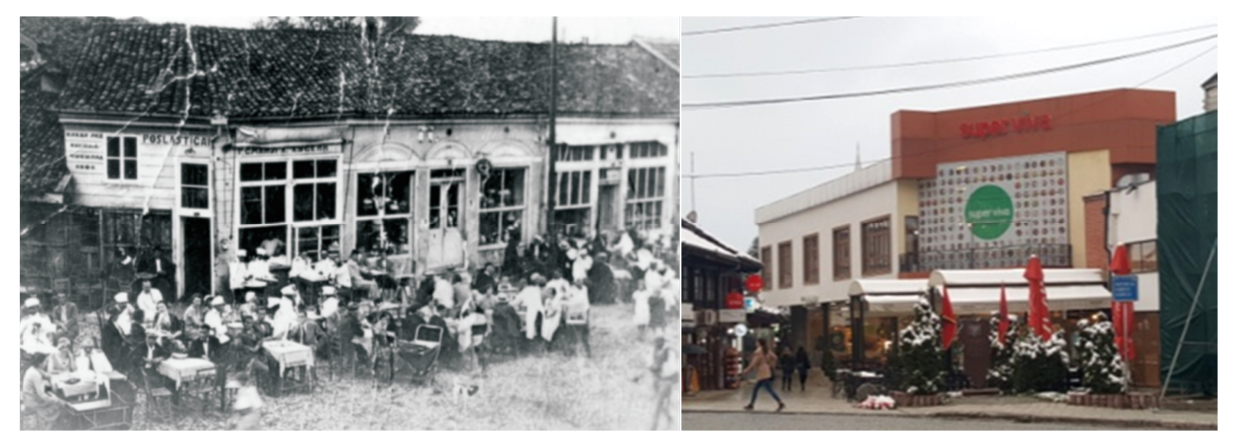

Fig. 5. The old handicraft center (left) [11] was destroyed in years 1967 to build the new shopping mall (right) (Photo: Besa Jagxhiu)

At present, the condition of the building in the heart of the Historic Center of Prizren is not good at all. A part of it is used as a supermarket, part as coffee shops, all with different styles and materials, and in disharmony with the area, thus, giving a bad image to the historic center (Fig. 6).

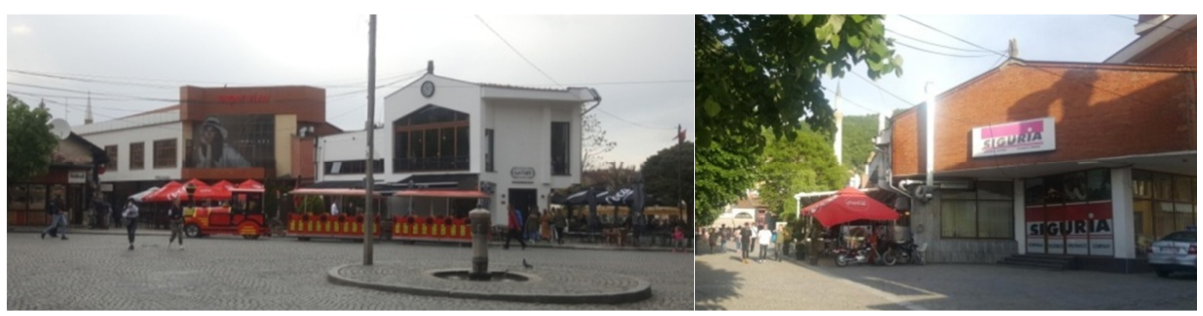

Fig. 6. The present state of the shopping mall in the Historic Center of Prizren (Photo: Besa Jagxhiu) 


\section{Proposal for the new contemporary shopping mall in the Historic Center of Prizren}

The current building in the first protective zone of the Historic Center of Prizren, which has neither architectural nor historic values is proposed by the author of the paper to be replaced with a new structure, new contemporary shopping mall, with innovative technology and construction materials, with the traditional city's handcrafts and modern crafts.

For the design proposal of the new shopping mall are taken into account four main aspects, functional, physical, socio-economic and cultural aspects. On the ground floor of the building are foreseen the attached trade shops with the traditional handicrafts of the city, thus creating harmony with the traditional architecture of the surrounded area. While on the first floor are foreseen the modern craft shops. In the front part of the building is located the attractive cafe restaurant with a beautiful panoramic view towards the historic center and the castle of the city, (Fig. 7 and Fig. 8).

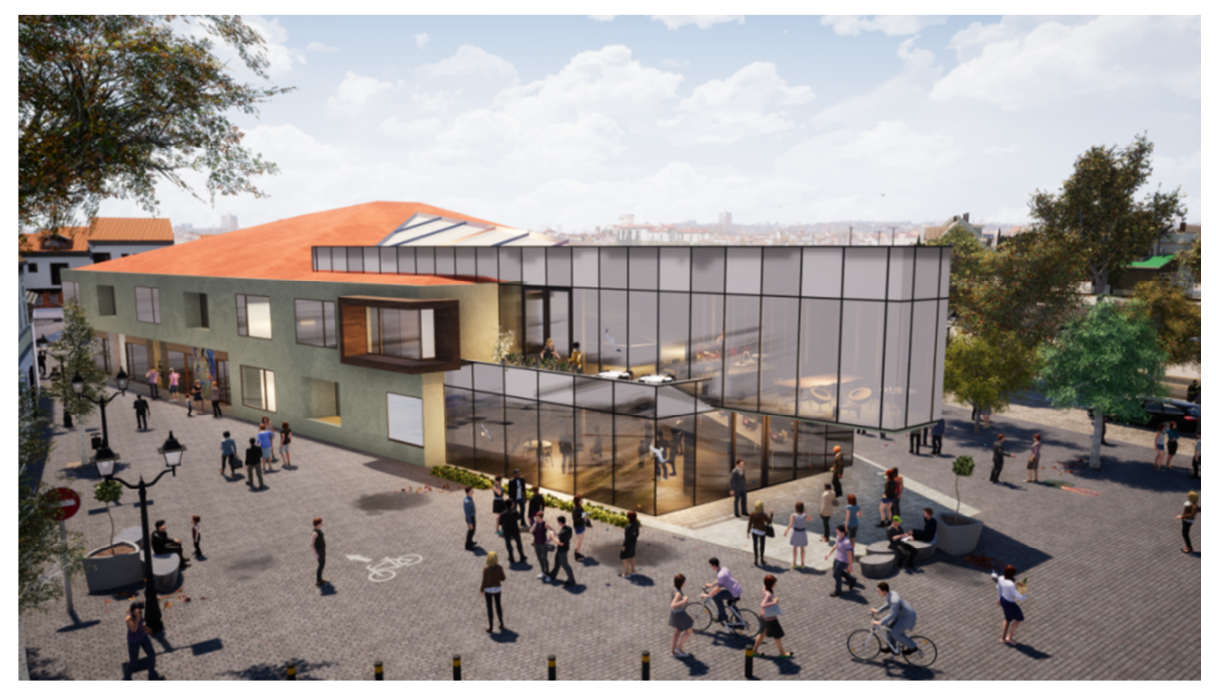

Fig. 7. The design proposal for the new contemporary shopping mall building in the Historic Center of Prizren, (Design: Besa Jagxhiu) (Software: ArchiCAD 21 [12])

The facade of the building with shop windows and entrances in the ground floor, the sloping roof with red clay tiles, as well as the façade colors are adapted to the traditional facilities of the area, while the frontal part of the building with the structural façade that reflects the monumental buildings of the historic center together creates an attractive architectural complex for the historic area. Proportions of the elements of the building are based on the traditional window, made up of modular panels.

New contemporary shopping mall with partnership funding, with the traditional city's handcraft and modern crafts could serve as the basis for the city's development 
strategy. This careful mix of old and new, cooperation between the private and public sector, promotion of traditional city handcrafts could be the added value to the Historic Center of Prizren.

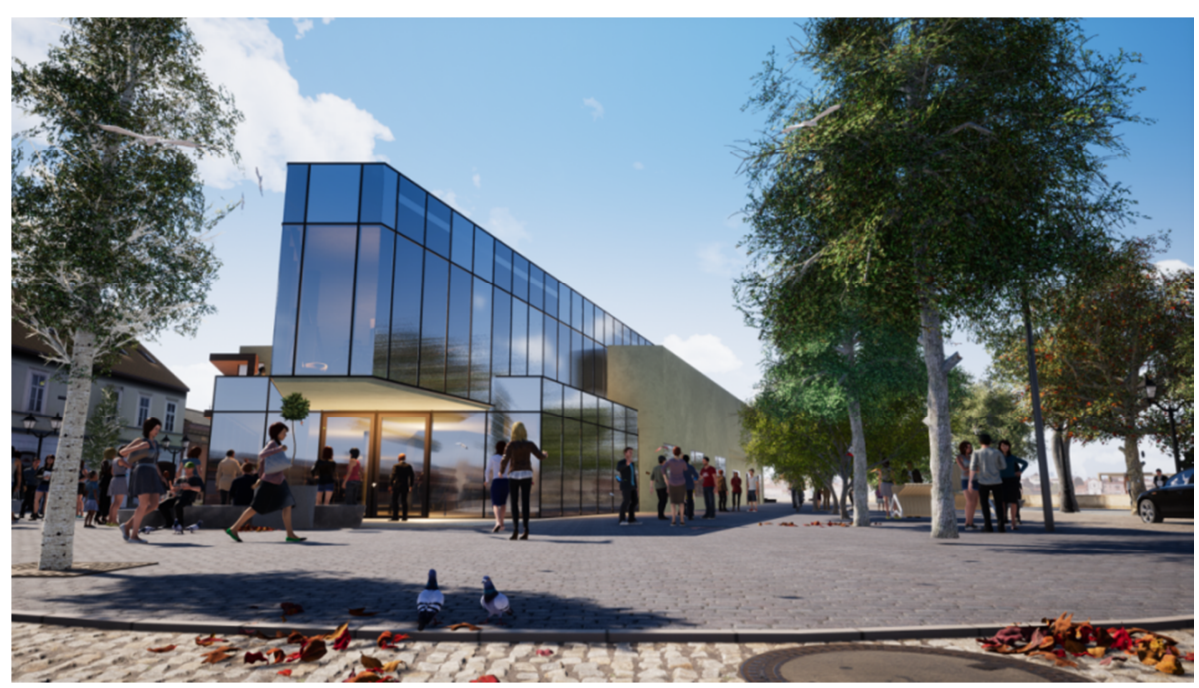

Fig. 8. The design proposal for the new contemporary shopping mall building in the Historic Center of Prizren (Design: Besa Jagxhiu) (Software: ArchiCAD 21 [12])

\section{Conclusion}

The historic protected zones have limited use; therefore a good planning framework for these zones is essential. Designing the new structures in the historical context is one of the most challenging tasks in the field since it is not easy to find harmony between the old and new. In the beginning, it was raised the question of how to incorporate the new structures harmoniously in the historic centers without endangering their cultural heritage values? For the appropriateness of the new designs, there are many different approaches and discussions; it should be based on international preservation standards and charters. On one side the new structures should reflect the time of their built in terms of innovation, technology, and material, and on the other should create harmony with the rest of the urban fabric of the zone.

Visually attractive buildings play a major role in promoting the city's identity. The new design in the historic center can be acceptable only if it respects and contributes to the city's identity and if it does not damage its cultural heritage values. The contemporary shopping mall in the Historic Center of Prizren should be designed to create an attractive place for citizens, tourists, and business owners, and at the same time avoiding deterioration of the historical place. The structure should be funded with the partnership between the private and public sector, and at the same time promoting the city's traditional handicrafts. 
Based on this proposed design for the Historic Center of Prizren could be redesigned and reused also many other similar buildings in the other cities in Kosovo, which during the socialist period are built as new trade malls in order to transform the old traditional trade centers, those destroying their cultural heritage values, and the most authentic parts of the historic cities.

\section{Acknowledgements}

This work has been undertaken as a part of a project founded by the Pollack Mihály Faculty of Engineering, University of Pécs.

\section{References}

[1] Wehdorn M. The Historic Centre of Vienna World Cultural Heritage and Vibrant Hub, City of Vienna, 2009.

[2] Demiri K. New architecture as infill in historical context, Architecture and Urban Planning, Vol. 7, 2013, pp. 44-50.

[3] Farahat B. I., Osman K. A. Toward a new vision to design a museum in historical places, HBRC Journal, Vol. 14, No. 1, 2018, pp. 66-78

[4] Topçu M., Kubat A. S. Old and new city: morphological analysis of Antakya, Proceedings on Eighth International Space Syntax Symposium, Santiago de Chile, 3-6 January 2012, pp. 8251-8251.

[5] Yee S. T., Yoh S. Rehabilitation methods and revitalization strategies in the old inner-city: Areas of rapid growth cities in Asia, A comparison of four cities: Penang, Hanoi, Shanghai and Tokyo, Proceedings of International Symposium on City Planning 2014, Hanoi, Vietnam, 6-8 November 2016, Urban and Regional Planning Review, Vol. 3, 2016, pp. $1-20$.

[6] Kovacs E. City success index, urban development, a possible method to research urban strategy, Pollack Periodica, Vol. 11, No. 3, 2016, pp. 27-42.

[7] Jagxhiu B., Kovács-Andor K. Prizren - Revitalizing the historic water channel system for modern city life, Pollack Periodica, Vol. 13, No. 1, 2018. pp. 157-168.

[8] Municipal profile - Prizren, June 2006, Organization for Security and Co-operation in Europe (OSCE).

[9] Conservation and Development Plan for the Historic Zone of Prizren, Prizren, 2008.

[10] State Geoportal, http://geoportal.rks-gov.net, (last visited 16 April 2019).

[11] Ec ma Ndryshe, Prizren through the Retrovisor. Prizren, 2010.

[12] GRAPHISOFT ArchiCAD, www.graphisoft.com, (last visited 16 April 2019). 